\title{
“And Harry doesn't mind if he doesn't make the scene..." Repensando a performance durante a pandemia de 2020
}

\author{
Fabio Soren Presgrave \\ Universidade Federal do Rio Grande do Norte \\ fabiopresgrave@musica.ufrn.br
}

Resumo: Relato de experiência vivido pelo Prof. Dr. Fabio Presgrave na Universidade Federal do Rio Grande do Norte, num arco temporal que nasce no atentado de 11 de setembro de 2001 e chega aos dias atuais, durante a pandemia COVID-19.

Palavras-chave: Performance, Pandemia, Violoncelo, Comunidade.

\section{"And Harry doesn't mind if he doesn't make the scene..." Rethinking Performance During 2020's Pandemic}

Abstract: Report of experience lived by PhD. Fabio Presgrave at the Federal University of Rio Grande do Norte, in a time lapse that starts from the Attack of September 11, 2001 and reaches the present day, during the COVID-19 pandemic.

Keywords: Performance, Pandemic, Cello, Community.

Este relato tem seu início em outra época em que o mundo para mim se transformou: o atentado contra o Word Trade Center de Nova Iorque, em 11 de Setembro de 2001. O ano letivo da Juilliard School acabara de começar e eu estava realizando o sonho de participar de classe de Joel Krosnick. Logo após esse dia terrível não conseguia estudar, ir às aulas e pedi para conversar com meu mestre. Naquela época ele me aconselhou da seguinte forma: "Vá para seu apartamento e desligue o rádio e a televisão. Mergulhe no seu fazer musical mesmo que mundo esteja se despedaçando a sua volta e a partir dessa experiência você vai começar a entender o que violoncelo e a música representam de uma forma mais profunda para você". Segui a proposta e aos poucos tudo foi paulatinamente 
se estabilizando. Nesses momentos nossa linguagem muda, aprendemos novos vocábulos e expressões. Em inglês a época me marcaram as palavras debri (detrito) e rubble (entulho), assim como hoje em dia ouvimos "entubar" e "novo normal".

Saltando no tempo para março de 2020, acredito que para muitos estudantes a sensação foi a mesma que tive em 2001, pois estavam iniciando seus cursos nas Universidades e as instituições suspenderam as atividades. A situação desses alunos é deveras mais dramática, pois a pandemia se estende até hoje; só no Brasil, está próxima a ceifar duzentas mil vidas.

Na minha família fomos infectados pelo vírus no final de Março, quando existiam poucos exames disponíveis e o desconhecimento sobre a doença era ainda maior. Após três semanas de convalescença recebi do meu estimado colega André Micheletti, professor da USP de Ribeirão Preto, uma chamada de vídeo em que ele se mostrava bem preocupado com a saúde mental dos alunos e queria pensar em estratégias para que pudéssemos mantê-los motivados nesse período. Fizemos então encontros conjuntos das classes de forma online e começamos a acompanhar a movimentação que surgia em torno das lives nas redes sociais.

Nesse momento comecei a conversar via Instagram com colegas do Brasil e do exterior, o que proporcionou uma experiência extremamente enriquecedora. Convidei com violoncelistas como: Wendy Law, Soo Bae, Alissa Weilerstein, Gustavo Tavares, Matias de Oliveira Pinto, Jaques Morelenbaum, Antonio del Claro, Marcio Malard, Mark Kosower, Martti Roussi, André Micheletti, Senja Rummukainen, Romain Garioud além de músicos como Daniel Guedes e Rapper Sagat B. Durante as lives, sempre abria-se espaço para participação do público, e foi muito interessante ver jovens músicos brasileiros interagindo com professores e artistas que normalmente não estariam facilmente a seu alcance. As ideias e inspirações que surgiram foram inúmeras e mereceriam um livro inteiro por si só, mas algo que me marcou especialmente foi o registro histórico da fala dos violoncelistas brasileiros. Acredito que para transcrever a emoção com que Antonio Lauro, Marcinho, Jaques, Matias e Gustavo contam suas trajetórias de vida eu teria que ter no mínimo a destreza de um Mia Couto, percebes? Nesta encarnação não seria possível. No entanto, relatando esse fato à Sonia Ray em uma de suas lives, ela me disse: "há muito tempo que sugiro para os pesquisadores que as 
entrevistas estejam em algum tipo de nuvem ao invés de realizar transcrições”. Sugestão anotada e adotada.

Após alguns meses, a volta ao ensino remoto se tornou uma necessidade. A princípio, muitos de nós rejeitamos a ideia de dar aulas de instrumentos de forma online, mas, com a continuação da pandemia, não tivemos outra escolha. De certa maneira, estávamos preparados, na UFRN. Em 2019, após acompanharmos a intensa movimentação das nossas instituições parceiras de países nórdicos com o ensino e ensaios online, decidimos, em plenária, realizar concurso para trazer um professor que fosse especialista no ensino de instrumentos utilizando as Tecnologias Digitais de Informação e Comunicação. O professor aprovado e contratado foi Julio Colabardini. Ao chegar à UFRN, o convidamos para participar do GRUVIO (Grupo de Grupo de Estudos sobre o Violoncelo, Violino, Viola e Contrabaixo nos Séculos XX e XXI) e nosso foco era o estudo da metodologia do ensino online de cordas, pois pretendíamos alcançar cidades do interior que ficavam a várias horas de viagem de Natal. Durante a pandemia, pesquisadores de universidades como UFMT, UFAL, IFPB, UFG, UFPI, USP, UFC e UFPA. Além do trabalho desenvolvido que inclui cursos online de violino, viola, violoncelo e contrabaixo gratuito para alunos de todas as regiões brasileiras que não têm acompanhamento regular de um professor o grupo de tornou uma verdadeira rede de apoio e de motivação, mal podemos esperar para termos nosso primeiro encontro presencial.

Em junho, recebi o convite do colega Flávio Gabriel para coordenar a classe de violoncelo do FIMUCA (Festival Internacional de Música em Casa). Confesso que nem cogitava a proporção que o evento tomaria. Flávio consegui reunir na versão de música de concerto dezesseis mil alunos. $\mathrm{Na}$ classe de cello, tivemos quinhentos alunos conectados, interagindo continuamente por uma semana. Foi emocionante ver os alunos interagirem com ícones e com a nova geração do violoncelo brasileiro. Foram muitas histórias, momentos emocionantes, como quando Morelenbaum tocou "Luiza" de Tom Jobim para o cellista Caio Michel de Teresina, que perdemos naquela semana para o COVID-19. Os grupos de WhatsApp e telegram borbulhavam e continuam assim até hoje, foram formados grupos paralelos que continuam em atividade como o de estudo do cello na música popular e o de estudo de alemão com violoncelistas. O mais marcante, no entanto, foi o último dia do Festival, quando o coração ficou apertado como em um 
encontro presencial. A prova de que qualquer evento funcionou é que a saudade bate antes que ele termine.

E afinal de contas o que o 'Harry' do Mark Knopfler e o Joel Krosnick têm com essa história toda? No dia 01 de Maio, Dia do Trabalho, um evento em Brasília me chocou bastante. Enfermeiras que estavam protestando pela falta de Equipamentos de Proteção Individual foram agredidas por manifestantes políticos radicais. Aquilo muito me sensibilizou e comecei a pensar o que poderia fazer para apoiar os profissionais da saúde que estavam colocando suas vidas em risco para defender a população. Como eu já tinha sido infectado pelo Coronavírus, tive a ideia de fazer pequenas apresentações nos hospitais, para que os profissionais da área respirassem e se sentissem, de alguma forma, abraçados. Levei a ideia ao Reitor da UFRN, que prontamente me colocou em contato com hospitais universitários e hospitais da rede pública. Aqui em nossa Universidade, temos o privilégio de ter um Reitor que sabe tocar violoncelo, seria muito bom termos mais gestores nas universidades brasileiras sabedores das dores e delícias de tocar um instrumento musical.

A primeira apresentação foi na Maternidade Januário Cicco, uma feliz coincidência, se é que elas existem. Dr. Cicco foi o padrinho do grande violoncelista Aldo Parisot. Quando visitei o Prof. Parisot no ano de 2014, em New Haven, ele me contou que teve uma fratura exposta depois de jogar futebol e foi até a casa do seu padrinho, que fez a redução sem anestesia. Esse primeiro dia me tomou com uma emoção diferente, algo que eu não sentia há anos tocando em público. Nós performers nos preparamos tanto para a perfeição técnica, com a roupa, com o repertório, que acabamos muitas vezes por nos esquecer do motivo que fez com que quiséssemos conviver com a música. Tocar com máscara pela primeira vez foi um desafio, com macas passando, sons de hospital, médicos apressados, tudo muito diferente. Naquele momento, existia uma energia que envolvia tudo e o Dó sustenido ter saído um pouco baixo não parecia ser um problema tão grave. Toquei naquele dia em uma UTI Neonatal pela primeira vez na vida, como posso eu ter passado vinte e cinco ano sem ter jamais ter tido essa experiência?

O primeiro concerto me deu uma nova motivação para estudar violoncelo. Eu queria trabalhar para tocar o melhor possível nos hospitais. Comecei a pensar sobre o ego e como ele nos atrapalha no estudo. Ficamos sentidos muitas vezes quando erramos em 
um concerto, quando temos um lapso de memória, mas geralmente esse incômodo é um desconforto egóico e não uma preocupação por não termos alcançado o que a música se propunha (If Harry doesn't mind if he doesn't make the scene, why should we?). Viajei para duas cidades do interior Santa Cruz e Currais Novos. No Hospital Mariano Coelho de Currais Novos, acompanhei a resposta das equipes de limpeza, fiz uma apresentação especial para eles. Esses heróis, tão esquecidos da mídia e da população, que se arriscam ao higienizar quartos infectados, muito me ensinaram. Um depoimento inesquecível foi o de uma senhora, que disse levar da pandemia uma coisa linda, que foi conhecer o violoncelo, algo que que jamais imaginou.

No Hotel Barreira Roxa, em Natal, toquei para profissionais da saúde que lá estavam hospedados sem poder voltar para casa, por terem parentes em situação de risco. Apresentei-me ao ar livre, com uma linda lua cheia e o mar de Natal. Uma enfermeira veio me agradecer ao final, dizendo que havia sido a primeira vez, em dois meses, que tinha se arrumado, já que a rotina dela consistia em ir ao hospital e dormir no hotel. Muitas vezes pensamos em aspectos tão supérfluos de nossas performances que esquecemos os motivos mais bonitos e humanos, que fazem as pessoas quererem ouvir música.

A partir desse momento comecei a me questionar sobre como chamamos o que fazemos. 'Música Clássica', ou 'Erudita', acho que já chegamos a um consenso, são termos que não se adequam. 'Música de Concerto' começou a me incomodar também. Quando toco no Hospital Municipal de Natal, aquilo não é um 'concerto', mas não é menos importante que qualquer apresentação nas nobres salas do Brasil. Não sei a resposta, será que é só 'Música' o termo que procuramos? 
Tocar nos hospitais me fez relembrar o poder que o violoncelo tem, quando o revelamos às pessoas pela primeira vez. Chegar com a caixa do instrumento em um local onde ninguém viu nada parecido, já causa impacto. Ao emitir os primeiros sons, as pessoas ficam mesmerizadas. Percebi que nunca toquei para meus vizinhos ou em reuniões de família, as pessoas tinham que ir às salas de concerto para me assistir. Será que realmente estive feliz, tocando? Essas apresentações me fizeram retomar o sentimento expresso pelo título de um livro muito interessante dos anos 1980, de Harry Wimmer: The Joy of Cello Playing.

Repensei sobre nossos cursos de bacharelado em instrumento, onde os alunos se apresentam tão pouco. Um ou dois recitais durante quatro anos de estudo árduo. Seria tão interessante que se apresentassem vinte ou trinta vezes por ano, em locais não formais, onde pudessem compartilhar a música e treinar para ser o que o presidente da Juilliard (Joseph Polisi) em 1996 disse á minha turma: “- You will have to be advocates for music!”

Algumas iniciativas da quarentena foram muito especiais. A série de conversas com Iberê Camargo, "Sons, Notas e Identidades", que trouxeram à tona assuntos cuja discussão é fundamental para todos nós. A tour de force que Sonia Ray empreendeu, reconectando tantas pessoas em torno do tema da pesquisa em música. O FIMUCA extrapolou todos os sonhos que tínhamos com relação aos números de pessoas interessadas no estudo da música, somadas as três edições, participaram mais de trinta mil pessoas!

Voltando ao Joel Krosnick, a lição que me foi ensinada em 2001 recomeçou em 2020: aprender qual o verdadeiro significado e missão de ser escolher a música como missão de vida. Apesar de ter aprendido esse tema voltado para meu interior durante a tragédia do 11 de Setembro, na pandemia deste ano descobri o significado que isso desperta, não somente para mim, mas o quanto ganho compartilhando minha música de forma simples e direta com as pessoas que me cercam e com a minha comunidade. 